$10 \mathrm{IKC}-354$

\title{
SEISMIC ANISOTROPY AND MANTLE STRUCTURE OF THE RAE CRATON, CENTRAL CANADA, FROM JOINT INTERPRETATION OF SKS SPLITTING AND RECEIVER FUNCTIONS
}

\author{
D. B. Snyder ${ }^{1}$, R.G. Berman ${ }^{1}$, J.-M. Kendall2 2, \& M. Sanborn-Barrie ${ }^{1}$ \\ ${ }^{1}$ Geological Survey of Canada, 615 Booth Street, Ottawa, Ontario K1A OE9 Canada; \\ Contact:dsnyder@NRCan.gc.ca; tel. (613)9929240 \\ ${ }^{2}$ Department of Earth Sciences, University of Bristol, Wills Memorial Building, Queens Road, Bristol BS8 1RJ, UK
}

Earthquakes recorded at 36 stations in Nunavut between 1992 and 2011 and analyzed jointly using receiver-function and SKS-splitting techniques indicate the presence of multiple, dipping layers beneath the northern Hudson Bay and Baffin Island region. Prominent discontinuities indicate layers interpreted to dip at $6-30^{\circ}$ at depths between 50 and $150 \mathrm{~km}$ beneath ten of the stations. One set of regionally continuous discontinuities in anisotropic fabric in the southeastern Rae craton dip gently southeast consistent with underthrusting beneath the Hearne and Meta Incognita-Sugluk blocks. SKS splitting recorded at eleven stations indicate patterns characteristic of two layers of anisotropic fabric. The deeper fabric as well as the single fast polarization direction recorded at other stations appears aligned with recent plate motion. The shallower fabric orientations at stations south of Repluse Bay are consistent with crustal structures formed during early (pre-1.85 Ga) stages of the Hudsonian orogeny. The shallower fabric north and west of Repulse Bay has a more northerly orientation and is associated with west-dipping discontinuities that may correspond to the Neoarchean accretion of the Mesoarchean northeastern Rae craton to the central Rae craton.
Interpretative cross section from the Rae $(\mathrm{K})$ to the Superior (AKV) cratons based on discontinuities revealed by receiver functions and the number of layers of distinct fabric revealed by SKS analysis; three-digit numbers are inferred fast polarization azimuth directions for that depth. The dashed blue line is the interpreted top surface of the Rae craton; $\mathrm{X}_{1,2,3}$ are interpreted discontinuities. Background shows transverse component receiver functions; responses to the north of each station represent back azimuth bins between $300^{\circ}-315^{\circ}$ that are available at each station; responses to the south of each station represent back azimuth bins between $165^{\circ}-182^{\circ}$. Approximate depth conversion was done using a single average velocity of $4.5 \mathrm{~km} / \mathrm{s}$.

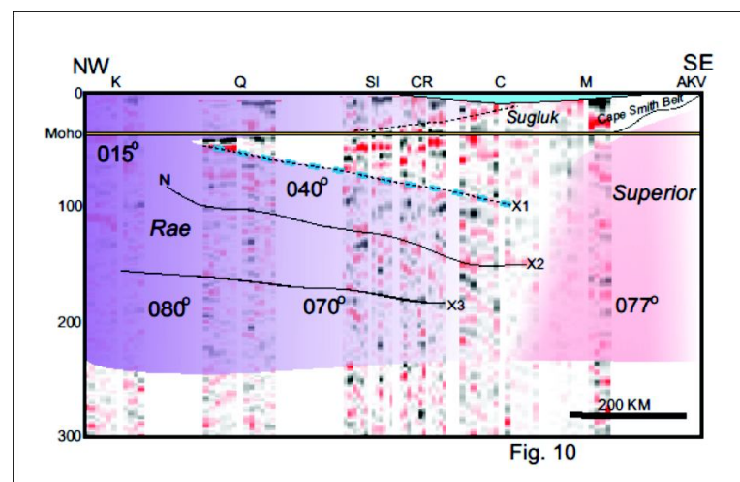


